\title{
El Caso Claude Reyes y el derecho de acceso a la información
}

\author{
The case of Claude Reyes and Freedom of Information Law
}

O Caso Claude Reyes e do direito de acesso à informação

DOI: http://dx.doi.org/10.23913/ricsh.v6i11.109

Luis Carlos Castro Vizcarra

Facultad de Derecho Mexicali, Universidad Autónoma de Baja California, México

luiscarloscastro@uabc.edu.mx

Alejandro Sánchez Sánchez

Facultad de Ciencias Administrativas y Sociales, Universidad Autónoma de Baja California, México

alexsasacc@uabc.edu.mx

Él Dr Alejandro Sanchez Sanchez (coautor) es director de tesis (Luis Carlos Castro Vizcarra)

\section{Resumen}

El propósito de este trabajo es comprobar si el Derecho de Acceso a la Información es un derecho humano, para lo cual se dan las definiciones de derechos humanos y derecho de acceso a la información pública, y a la vez se toma en cuenta la opinión de la Corte Interamericana de Derechos Humanos, jurisprudencia válida en nuestro sistema jurídico. El caso más importante que se encontró es el de Claude Reyes vs Chile, parte central de esta investigación, donde se estableció que el derecho de acceso a la información es un derecho humano por sí solo. En consecuencia, la Corte Interamericana fue el primer organismo internacional en reconocerlo en una sentencia.

Palabras clave: acceso, información, derecho humano, Claude Reyes.

\section{Abstract}

The purpose of this work is to check if the Freedom of Information Law is a Human Right, to do so, the definitions of Human Rights and Freedom of Information Law are given, and at the same 
time taking into account the opinion of the Inter-American Court of Human Rights, valid law in our legal system. The most important case that was found is that of Claude Reyes vs Chile, central part of this research, where it is established that the Freedom of Information Law is a human right by itself. As a result, the Inter-American Court was the first international agency to recognize it in a sentence.

Key words: Freedom of Information, access, information, Human Rights, Claude Reyes.

\section{Resumo}

O objetivo deste trabalho é verificar se o direito de acesso à informação é um direito humano, para o qual as definições de direitos humanos e direito de acesso à informação pública, constam ainda tido em conta o parecer do Corte Interamericana de Direitos Humanos, a jurisprudência válida em nosso ordenamento jurídico. O caso mais importante foi encontrado é o de Claude Reyes vs. Chile, parte central desta investigação, onde foi estabelecido que o direito de acesso à informação é um direito humano em si. Assim, o Tribunal foi a primeira organização internacional a reconhecê-lo em uma frase.

Palavras-chave: acesso, informação, direito humano, Claude Reyes.

Fecha Recepción: Julio 2016 Fecha Aceptación: Enero 2017

\section{Introducción}

El derecho de acceso a la información es un derecho humano reconocido en nuestra constitución en su artículo $6^{\circ}$ (Constitución Política de los Estados Unidos Mexicanos, 1917), así como en el artículo $13^{\circ}$ de la Convención Americana sobre Derechos Humanos (1969), el $19^{\circ}$ de la Declaración Universal de los Derechos Humanos (1948), y el Pacto Internacional de Derechos Civiles y Políticos (1966), todos ellos tratados internacionales de los que México forma parte.

Asimismo, el artículo sexto constitucional establece todo un mecanismo de garantía del propio derecho, conformado por un órgano garante nacional (Instituto Nacional de Acceso a la Información Pública) y organismos locales (en Baja California el Instituto de Transparencia y Acceso a la Información Pública). Ahí se establecen principios como el de máxima publicidad y 
que todas las personas sin necesidad de acreditar interés alguno pueden hacer valer dicho derecho.

A nivel internacional no se goza del mismo sistema de garantía ya que no existe un organismo internacional garante de dicho derecho de manera particular o especializada. Los tratados internacionales, al menos la Declaración Universal sobre Derechos Humanos, la Convención Americana sobre Derechos Humanos y el Pacto Internacional de Derechos Civiles y Políticos, ubican al derecho de acceso a la información como un derecho accesorio a la libertad de expresión. Sin embargo, la práctica e inclusive en el sistema Americano, la Corte Interamericana ha establecido que el derecho de acceso a la información en sí es un derecho humano.

"Los principios de interdependencia e indivisibilidad de los derechos humanos a los que se refiere el párrafo tercero del primer artículo de nuestra constitución, establecen que todos los derechos humanos existen al mismo tiempo" (Vázquez y Serrano, 2012), por lo que es necesario establecer mecanismos de convivencia de los propios derechos. Las obligaciones de proteger, garantizar, promover y respetar los derechos humanos, consagrados en el mismo artículo, aplican para el derecho de acceso a la información y para todas nuestras autoridades.

"El derecho de Acceso a la Información se encuentra directamente relacionado con la rendición de cuentas, la transparencia y la participación ciudadana y es un elemento esencial en cualquier gobierno democrático" (Castro, 2014), que puede ser utilizado como herramienta para mejorar la calidad de vida de los ciudadanos "ya que en su ejercicio descansa una parte importante de la confianza que los gobernados puedan tener sobre los gobernantes" (Castellanos, 2004).

\section{MÉTODO}

La problemática planteada requiere de su sistematización, para ello es necesario buscar dar respuesta a las interrogantes y alcanzar los objetivos planteados, buscando demostrar las hipótesis establecidas. Esto se logrará con un enfoque cuantitativo y cualitativo, así como con un alcance exploratorio, descriptivo, correlacional y explicativo de la investigación, utilizando como unidad de análisis "el derecho de Acceso a la Información en México" y la "garantía constitucional para su protección" con un diseño de investigación no experimental, transversal, utilizando técnicas de investigación documental y de campo. 
Las interrogantes fundamentales a responder son las siguientes:¿cuál es el derecho de acceso a la información pública en México?, ¿cuál es la naturaleza jurídica del derecho de acceso a la información pública en México?, ¿cuál es la garantía constitucional para la protección del derecho de acceso a la información pública en México?, ¿cuál es la base constitucional, convencional y legal de la garantía constitucional para la protección del derecho de acceso a la información pública en México?, ¿cuál ha sido el uso cuantitativo y cualitativo del derecho de acceso a la información pública en México?

Los objetivos establecidos para la investigación son los siguientes:

- Ubicar el derecho de acceso a la información pública en México.

- Definir la naturaleza jurídica del derecho de acceso a la información pública en México.

- Establecer la garantía constitucional para el derecho de acceso a la información pública en México.

- Fundar las bases constitucionales, convencionales y legales de la garantía constitucional, para la protección del derecho de acceso a la información pública en México.

- Indagar y analizar el uso cuantitativo y cualitativo del derecho de acceso a la información pública en México.

- Determinar los efectos de la garantía constitucional para la protección del derecho de acceso a la información pública en México.

Se considera que las interrogantes y objetivos planteados se plasman de forma enunciativa y no limitativa. Si es necesario replantearlos se hará durante la ampliación de esta investigación.

\section{RESULTADOS}

Marcel Claude Reyes, Sebastián Cox Urrejola y Arturo Longton, ciudadanos chilenos, presentaron una petición a la Comisión Interamericana de Derechos Humanos en diciembre de 1998, representados por el abogado Juan Pablo Olmedo Bustos, conocido por la sentencia "La última Tentación de Cristo". 
La petición era por la negativa del Estado chileno de brindar información relacionada a un proyecto de industrialización forestal, así como la ausencia de un recurso efectivo para cuestionar dicha decisión (Corte Interamericana de Derechos Humanos, 2008).

En mayo de 1998, Claude Reyes, director de la Fundación Terram, solicitó al Comité de Inversiones Extranjeras información relacionada con un proyecto de industrialización forestal, pero su solicitud fue denegada. En julio del mismo año, Reyes (representando a Terram), Cox (representando a la ONG Forja) y Longton (diputado chileno), presentaron un recurso de protección ante la Corte de Apelaciones de Santiago. Dicho recurso se presentó debido a la negativa de la CIE de brindar información acerca del proyecto; no obstante, el recurso fue declarado inadmisible (CIDH, 2008).

El 17 de diciembre de 1998, los tres chilenos presentaron la petición a la Comisión Interamericana, y fue admitida el 10 de octubre de 2003 y emitido un informe de fondo en marzo de 2005. La Comisión decidió remitir el caso a la Corte Interamericana en julio de 2005 (CIDH, 2008).

La Comisión le solicitó a la Corte que declarara responsable al Estado chileno por la violación de los artículos $13^{\circ}$ y $25^{\circ}$ de la Convención Americana, los cuales nos hablan del acceso a la información y protección judicial respectivamente. El tribunal internacional coincidió con las violaciones alegadas por la Comisión y estimaron también violados los artículos $8^{\circ}$ y $23^{\circ}$ del tratado, que hablan sobre las garantías judiciales y los derechos políticos respectivamente (CIDH, 2008).

La solicitud de Reyes fue sobre un proyecto de explotación forestal en la provincia de Magallanes, conocido como Río Cóndor, y su finalidad era medir su impacto en el medio ambiente. El proyecto lo encabezaría la empresa extranjera Forestal Trillium, pero nunca fue llevado a cabo quizá por la presión política y mediática que generó la solicitud, pero el caso sentó un precedente emblemático sobre el Derecho de Acceso a la Información (Olmedo Bustos, 2006).

El análisis sobre el acceso a la información y el caso Claude Reyes confirma que, en la medida en que haya confianza en que las autoridades hacen públicos todos los documentos que generan o tienen en su poder y que solamente se reservan la información que pone en peligro la seguridad 
nacional o el interés público, es posible avanzar hacia la consolidación democrática de nuestro país, mejorar las áreas administrativa, regulatoria y gubernamental de México, y tener cada vez más confianza, apertura, transparencia y verdadera participación ciudadana. Por sí solos, estos factores ayudan a incrementar el rendimiento institucional.

La garantía del derecho de acceso a la información beneficia de manera directa a todas las personas que utilizan los sistemas y portales de internet: los medios de comunicación, investigadores, estudiantes, la oposición, sociedad civil organizada, entre otros; pero de manera indirecta también afecta a todos los individuos, ya que tener real acceso a la información puede generar mejores condiciones de trabajo, mayor competitividad, nuevas oportunidades de negocio, estudios y análisis apegados a la realidad, entre otras muchas ventajas.

El derecho de Acceso a la Información nos permite tener acceso a todos los documentos generados o que están en poder de las autoridades (Ley Federal de Transparencia y Acceso a la Información Pública Gubernamental, 2002). Es información estadística que puede servir para nuestro negocio, pues contiene incluso los precios de compra de varios productos que el propio gobierno puede utilizar, lo que puede servir para elaborar una propuesta de venta al gobierno por parte de las empresas. Asimismo ayuda a posibles inversionistas y generadores de empleo a que tengan una idea de la realidad económica y social del país.

Los órganos garantes son los que deben revisar la información reservada y resolver los recursos interpuestos por los ciudadanos inconformes sobre la clasificación de la información pública. A nivel federal existe el Instituto Federal de Acceso a la Información Pública y Protección de datos (IFAI), y en Baja California el Instituto de Transparencia y Acceso a la Información Pública de Baja California (ITAIPBC). Mientras mayor credibilidad tengan estos organismos, más será el uso de los sistemas de acceso de información y mayor será la confianza de los usuarios hacia las solicitudes y sus respuestas.

Nuestra ley estatal no tiene una sanción expresa contra las autoridades que reserven información y no cumplan con las características que las leyes señalan; la ley de transparencia solamente nos refiere a la ley de responsabilidades, la cual tampoco establece una sanción específica para dicho acto. La ausencia de dicha sanción hace que las autoridades reserven muchos documentos sin cumplir con los requisitos constitucionales y legales, lo cual contribuye a la opacidad gubernamental y lesión de la transparencia. 
Las autoridades estatales no cumplen con el mandato constitucional en cuanto a los requisitos legales establecidos por las normas locales y federales de transparencia y el test de proporcionalidad que establece la doctrina y la corte en materia de límites de los derechos humanos al reservar documentos públicos.

En una breve investigación realizada en el portal de transparencia del ITAIPBC, se encontró que más del $60 \%$ de los recursos que se interpusieron ante el mismo Instituto, desde 2013 a la fecha, en contra de los sujetos obligados del Estado, se resolvió en contra de las autoridades, a quienes se ordenó dar la información sin modificarla (Instituto de Transparencia y Acceso a la Información Pública, 2013). En muchos casos, la autoridad clasificó como reservada la información de carácter público.

El mismo artículo $6^{\circ}$ constitucional establece que en nuestro país debe imperar el principio de máxima publicidad, el cual dicta que en caso de duda si la información debe entregarse o no, la autoridad debe optar por la primera opción. Esto no parece ser el caso en Baja California debido a la gran cantidad de recursos (184 en 2014) (ITAIP, 2014) interpuestos ante el Instituto.

Existe falta de confianza por parte de los habitantes del estado de Baja California en solicitar información a las autoridades, eso se puede manifestar por las demandas interpuestas por parte de la sociedad civil organizada, como es el caso de OBSERBC A.C., entre otras.

Otro punto importante es la demora con la que la autoridad cataloga la información y responde a las solicitudes; en algunos casos la autoridad estatal no cataloga la información hasta que le llega la solicitud, en otros casos toma el tiempo máximo (diez días hábiles) para informar que los documentos se consideran reservados.

En la página del gobierno del Estado y algunos otros sujetos obligados podemos encontrar los catálogos de información pública reservada. En el caso del ejecutivo estatal existen páginas completas de información que se considera reservada, en otras autoridades no encontramos estos catálogos por lo que no podemos saber exactamente cuántos documentos están reservados, lo cual disminuye la confianza y la transparencia.

Otro síntoma de la falta de transparencia y el exceso de opacidad es la facilidad con que la autoridad estatal reserva la información. En muchos casos no está fundamentada la reserva de la información, en otros se reserva información que claramente no debería estar clasificada así, y además el proceso de desclasificación (recurso) es muy lento pues puede durar hasta doce meses o más. 
Baja California promulgó su segunda Ley de Transparencia en 2010, la cual abrogó la de 2005, por lo que se creó el Instituto de Transparencia y Acceso a la Información Pública, un órgano garante constitucional autónomo. Vale la pena recalcar que nuestro estado fue el último del país en tener dicho organismo.

De todo lo anterior podemos concluir que: organismos garantes con mayor credibilidad, sanciones a los servidores públicos que no cumplan con la ley de transparencia, restricciones a reservar y ocultar información, ayudan al ejercicio del derecho de acceso a la información, que a su vez ayuda a tener mayor transparencia y confianza en nuestras instituciones, lo que fortalece la competitividad en nuestro estado.

La sentencia de Claude Reyes es importante porque crea un precedente internacional sobre la importancia del Derecho de Acceso a la Información y el interés general de difundir los documentos públicos.

\section{DISCUSIÓN}

El derecho al acceso a la información pública en el sistema jurídico mexicano se basa en el artículo $6^{\circ}$ de la Constitución Política de los Estados Unidos Mexicanos, cuyo segundo párrafo establece que: "Toda persona tiene derecho al libre acceso a información pública y oportuna, así como a buscar, recibir y difundir información e ideas de toda índole por cualquier medio de expresión" (1917).

Más adelante, el mismo artículo indica que: “Toda la información en posesión de cualquier autoridad, entidad, órgano y organismo de los Poderes Ejecutivo, Legislativo y Judicial, órganos autónomos, partidos políticos, fideicomisos y fondos públicos, así como de cualquier persona física, moral o sindicato que reciba y ejerza recursos públicos o realice actos de autoridad en el ámbito federal, estatal y municipal, es pública" (1917).

Toda la información es pública, sin embargo, podrá reservarse su acceso temporalmente por razones de interés social y seguridad nacional, como lo establece el propio artículo sexto y las leyes. Cuando se interprete el Derecho de acceso a la información, la Constitución establece que debe prevalecer el principio de máxima publicidad (1917).

Por lo tanto, es importante señalar que la Constitución imprime que: "Los sujetos obligados deberán documentar todo acto que derive del ejercicio de sus facultades, competencias o 
funciones, la ley determinará los supuestos específicos bajo los cuales procederá la declaración de inexistencia de la información" (1917).

Si se consulta la Constitución local, es decir, del Estado Libre y Soberano de Baja California, encontramos que el artículo $7^{\circ}$ apartado $\mathrm{C}$ señala lo siguiente: "Toda persona sin necesidad de acreditar interés alguno, tiene derecho a acceder a la información que la ley clasifica como pública, a sus datos personales, o a la rectificación de estos. La Ley de la materia deberá observar, entre otros, los principios de protección a los datos personales, máxima publicidad y gratuidad; asimismo, deberá establecer los mecanismos de acceso a la información pública, de protección de los datos personales, así como los procedimientos de revisión, y señalar aquella que tenga el carácter de reservada o confidencial" (Constitución Política del Estado Libre y Soberano de Baja California, 1953).

En cuanto a la definición de información pública en el Estado, es necesario remitirnos a la Ley de Transparencia y Acceso a la Información Pública para el Estado de Baja California, cuyo artículo $3^{\circ}$ señala que: "La información generada, administrada o en posesión de los sujetos obligados, se considera un bien de dominio público, por lo que cualquier persona tendrá acceso a la misma en los términos y con las excepciones que esta Ley señala. Su reglamento no podrá establecer más excepciones que las previstas en este ordenamiento" (Ley de Transparencia y Acceso a la Información Pública de Baja California, 2010).

En el ámbito internacional, el Derecho de Acceso a la Información se encuentra de la mano de la libertad de expresión. En la Declaración Universal de Derechos Humanos, en el artículo 19, se indica lo siguiente: "Todo individuo tiene derecho a la libertad de opinión y de expresión; este derecho incluye el de no ser molestado a causa de sus opiniones, el de investigar y recibir informaciones y opiniones, y el de difundirlas, sin limitación de fronteras, por cualquier medio de expresión" (1948).

El Pacto Internacional de Derechos Civiles y Políticos (1966) sigue la misma línea, y en su artículo 19.2 establece: "Toda persona tiene derecho a la libertad de expresión; este derecho comprende la libertad de buscar, recibir y difundir informaciones e ideas de toda índole, sin consideración de fronteras, ya sea oralmente, por escrito o en forma impresa o artística, o por cualquier otro procedimiento de su elección".

En el Sistema Americano de Derechos Humanos podemos encontrar que el artículo $13^{\circ}$ del Pacto de San José (1969) asocia, también, el derecho de acceso de información con el de libertad de 
expresión al señalar lo siguiente: "Toda persona tiene derecho a la libertad de pensamiento y de expresión. Este derecho comprende la libertad de buscar, recibir y difundir informaciones e ideas de toda índole, sin consideración de fronteras, ya sea oralmente, por escrito o en forma impresa o artística, o por cualquier otro procedimiento de su elección".

El vocablo acceso, según la Real Academia de la Lengua, significa "la acción de llegar o acercarse". Por información pública, vimos que la ley se refiere a la contenida en los documentos que los sujetos obligados generen, obtengan, adquieran, transformen o conserven por cualquier título. La misma ley establece que documentos es cualquier registro que documente el ejercicio de las facultades o su actividad en cualquier medio, sea visual, impreso, sonoro, escrito, electrónico u holográfico.

Podemos entonces concluir que el Derecho de Acceso a la Información es la prerrogativa que tiene cualquier persona, sin acreditar interés alguno, de llegar a los documentos que generen, obtengan, adquieran, transformen o conserven los sujetos obligados en cualquier medio.

El DAI (Derecho de Acceso a la Información Pública) siempre se asocia con la transparencia y la protección de datos, lo podemos ver en el nombre de las leyes (Ley de Transparencia y Acceso a la Información Pública Gubernamental) como en los órganos garantes (Instituto Federal de Acceso a la Información Pública y Protección de Datos), y aunque son cuestiones diferentes, todos protegen el mismo derecho: el del acceso a la información pública, ya sea por obligación del gobierno a transparentar sus documentos o por proteger los datos confidenciales de las personas.

El vocablo transparencia proviene del adjetivo "transparente", que sugiere una calidad de un cuerpo que deja ver claramente sus objetos, que permite dejar pasar la luz, que es translúcido, que es evidente o que se comprende sin duda ni ambigüedad. Aplicado a la filosofía política, se entiende como una obligación por parte de los servidores públicos de dar a conocer los actos y documentos de su administración, especialmente el uso del dinero público, para prevenir la corrupción. Los organismos e instituciones de gobierno deben de simular colocar toda la información en una caja de cristal, transparente, por donde pase no solamente la luz sino los ojos de los ciudadanos y de la opinión pública.

Si bien es cierto que la transparencia surge como una demanda de la sociedad, para saber qué hace el gobierno con el dinero de nuestros impuestos, la práctica de esta actividad ha dado muchos beneficios metapolíticos, pues se trata de compartir información que puede ser útil para 
la ciudadanía, empresas, asociaciones civiles y agrupaciones que pueden verse beneficiadas de muchas maneras al tener información de fácil acceso, real y concisa que el gobierno a través de sus diversas actividades recaba, genera o resguarda.

El Acceso a la Información debe entenderse como un derecho humano, consagrado por nuestra Constitución y que le da a cualquier persona, sin necesidad de acreditar interés alguno, la prerrogativa de hacerse de cualquier documento que cualquier servidor público genere, resguarde o tenga a su alcance. Existen excepciones al acceso a la información, como la información reservada, que es información pública que se guarda en custodia por un tiempo determinado con la finalidad de proteger algún otro derecho si se llega a difundir, como puede ser la vida, la seguridad o la gobernabilidad. Del mismo modo, también existe la información confidencial, la cual nunca se da a conocer y se guarda en secreto al consistir en datos personales de los habitantes del Estado. Sin embargo, en nuestro país debe imperar el principio de máxima publicidad que señala la Constitución (Castro Vizcarra, 2014).

El DAI en el sistema americano, como observamos en el subcapítulo anterior el Derecho de Acceso a la Información, se encuentra consagrado en los tratados internacionales en la libertad de expresión, sin embargo, vamos a revisar algunas sentencias y documentos donde la Corte Interamericana y la Comisión Interamericana establecen que el Derecho de Acceso a la Información es un derecho humano por sí solo.

El Derecho de Acceso a la Información, como se conoce ahora, surgió a partir de los años noventa. Sus primeros intentos fueron en los años setenta, con la reforma constitucional de 1977 al artículo sexto, sin embargo, este sólo establecía que se garantizaría el Derecho de Acceso a la Información, pero no decía cómo. No fue sino hasta el año 2002 que en nuestro país se crearon la ley y el órgano que garantizarían este derecho.

Tomando en cuenta los antecedentes históricos del Derecho de Acceso a la Información podemos ver porqué en los tratados firmados en 1949, 1966 y 1969 no se establecía al Derecho de Acceso a la Información en un artículo propio sino como parte de la libertad de expresión.

La relatoría especial para la libertad de expresión de la Comisión Interamericana de Derechos Humanos estableció en 2012 que: "El Derecho de Acceso a la Información es un derecho fundamental protegido por el artículo $13^{\circ}$ de la Convención Americana. Se trata pues, de un derecho particularmente importante para la consolidación, el funcionamiento y la preservación de los sistemas democráticos, por lo cual ha recibido un alto grado de atención, tanto por los 
Estados miembros de la OEA como por la doctrina y la jurisprudencia internacional" (CIDH, 2014).

La propia Relatoría Especial en el mismo documento nos da un concepto a través de su interpretación: "El artículo $13^{\circ}$ de la Convención Americana comprende la obligación positiva en cabeza del Estado de permitir a los ciudadanos acceder a la información que está en su poder" (CIDH, 2014). Esto despeja toda duda de que el artículo $13^{\circ}$ no sólo abarca el Derecho de Acceso a la Información en el sistema Americano, sino que es en sí un derecho humano, diferente e importante para la consolidación de los sistemas democráticos.

Inclusive "la Corte Interamericana ha establecido que el artículo $13^{\circ}$ de la Convención Americana, al estipular expresamente los derechos a buscar y a recibir informaciones, protege el derecho que tiene toda persona a acceder a la información bajo el control del Estado, con las salvedades permitidas bajo el estricto régimen de restricciones establecido en dicho instrumento" (CIDH, 2014). Si bien esto es cierto, habla de un control por parte del Estado y también señala el contenido y el alcance del derecho y que las restricciones deben ser mínimas.

Podemos encontrar otras evidencias donde la Corte reconoce que es un nuevo derecho humano inclusive en las sentencias de los casos Claude Reyes y otros y Gomes Lund y otros (Guerrilha do Araguaia). La Corte ya no se refirió a la formulación clásica del artículo $13^{\circ}$ de la Convención Americana (en términos de la libertad de expresión) y más bien sostuvo la existencia de un nuevo derecho humano (Bertoni y Zelada, 2014).

La decisión de la Corte Interamericana de afirmar que el acceso a la información constituye un derecho fundamental es considerada histórica por muchas organizaciones protectoras de los derechos humanos, pues fue el primer tribunal internacional en hacerlo (Bertoni y Zelada, 2014).

\section{CONCLUSIÓN}

Los derechos humanos son un tipo de derechos que se enfocan en proteger la dignidad y los bienes básicos, que crean obligaciones para las autoridades y cuya positivización es muy importante. Están dotados de características especiales: son inherentes a la persona, incondicionales, trasnacionales, inalienables, irrenunciables, imprescriptibles e irreversibles. Sin embargo, los derechos humanos no son absolutos, es decir, es necesario limitarlos para que impidan avasallar otros derechos humanos entendiendo que son indivisibles e interdependientes (Carbonell, 2014). 
El propósito de este trabajo es comprobar que el Derecho de Acceso a la Información es un derecho humano, y por ello primero definimos qué son los derechos humanos, después qué es el Derecho de Acceso a la Información Pública y, por último, buscamos opiniones de la Corte Interamericana de Derechos Humanos, jurisprudencia que aplica a nuestro sistema jurídico (Steiner, 2014), sentencias que enumeramos y donde la Corte establece que en efecto el Derecho de Acceso a la Información es un derecho humano.

El agregar el DAI al catálogo de Derechos Humanos de nuestro país es un avance importante, pues genera las obligaciones a las autoridades de promover, garantizar, respetar y proteger dicho derecho con los principios de interpretación conforme y pro-persona, obligando al Estado a sólo limitarlo cuando entra en conflicto con otro derecho humano y a crear las condiciones necesarias para que dicho derecho se ejerza.

El propósito final de la investigación es aplicar principios convencionales a los límites del Derecho de Acceso a la Información, en particular a la reserva temporal de la información por parte de la autoridad, con el fin de fortalecer este derecho y restringir el límite del mismo a los casos en los que sea estrictamente necesario y que cumplan con los requisitos que establece la Constitución y el Sistema Americano de Derechos Humanos.

La sentencia de Claude Reyes y otros vs Chile, es una parte importante para nuestro trabajo ya que nos ayudará a establecer los principios convencionales y la opinión de la Corte Interamericana sobre el DAI.

Este estudio aporta un fundamento importante para considerar al Derecho de Acceso a la Información como un derecho fundamental que requiere de los principios rectores y obligaciones y deberes que conllevan. El Estado, en el caso de México, es el responsable de permitir el acceso a la información pública para todo habitante de los Estados Unidos Mexicanos, reservando aquella información que sea estrictamente necesaria para la seguridad nacional y la privada, y con ello contribuir a la consolidación de un estado de Derecho que permita el goce de los derechos fundamentales dentro del marco constitucional y convencional de los que México forma parte. 


\section{Bibliografía}

Bertoni E. y Zelada C. (2014). Artículo 13 Libertad de pensamiento y expresión, "Convención Americana sobre Derechos Humanos comentada”. México: SCJN.

Carbonell, M. y Salazar, P. (coord.). (2012). La reforma constitucional de derechos humanos: Un nuevo paradigma. México: SCJN/IIJ/UNAM.

Carbonell, M. (15 de abril de 2014). 28. Los límites de los Derechos Humanos. Recuperado de:https://www.youtube.com/watch?v=cSkZdtwRpLc\&index=28\&list=PL14tmFGP4Lr0t MrMHoOjft7FWlEAI-vwo. Consultado el 10 de mayo de 2016.

Carbonell, M. (2014). Constitucionalismo y democracia. Ensayos críticos. México: Porrúa. Recuperado de http://www.miguelcarbonell.com/articulos/Globalizaci_n_ y_derecho.shtml. Consultado el 12 de mayo de 2016.

Castellanos Gout, M. E. (2004). Del Estado de Derecho al Estado de Justicia, México: Porrúa.

Castro Vizcarra, L. C. (2014). Transparencia en las Universidades Autónomas, Autonomía y auditoría universitarias. México: UABC.

Corte Interamericana de Derechos Humanos (2008). "Ficha Técnica: Claude Reyes y otros vs. Chile". www.corteidh.or.cr/tablas/fichas/claudereyes.pdf

Freedman, Thomas. (2005). "The World is Flat: A Brief History of the Twenty-First Century". Farrar, Straus and Giroux, Estados Unidos.

Instituto de Transparencia y Acceso a la Información Pública de Baja California. (2014). Reporte $\begin{array}{lllll}\text { de } & \text { Recursos } & \text { de } & \text { Recuperado }\end{array}$ http://www.itaipbc.org.mx/index.php/transparencia/art21fracciperiodo/

Kaplan, M. (2002). El sistema internacional: límites, paradojas y posibilidades. En J. L. Valdés Ugalde y D. Valadés (coord.), Globalidad y conflicto. Estados Unidos y la crisis de septiembre. México: CISAN, UNAM, IIJ.

Olmedo Bustos, Juan Pablo (2006). "Condenan a Chile por negar acceso a información pública". Recuperado de: América Latina en Movimiento. http://www.alainet.org/es/active/13862. Consultado el 23 de mayo de 2016.

Relatoría Especial para la Libertad de Expresión de la Comisión Interamericana de Derechos Humanos (2012). "El Derecho de Acceso a la Información en el Marco Jurídico Interamericano”, Comisión Interamericana de Derechos Humanos, $2^{a}$ edición. 
Steiner C. y Uribe P. (coord.). (2014). Convención Americana sobre Derechos Humanos comentada. México: SCJN.

Vázquez, L. D. y Serrano, S. (2013). Los principios de universalidad, interdependencia, indivisibilidad y progresividad. Apuntes para su aplicación práctica. México: Porrúa.

Zweigert, K. y Kotz, H. (2002). Introducción al derecho comparado. México: Oxford University Press.

\section{REFERENCIAS NORMATIVAS}

Constitución Política de los Estados Unidos Mexicanos (1917).

Convención Americana sobre Derechos Humanos (1969).

Declaración Universal de los Derechos Humanos (1948).

Ley Federal de Transparencia y Acceso a la Información Pública Gubernamental (2002).

Ley para el Desarrollo de la Competitividad de la Micro, Pequeña y Mediana Empresa (2002).

Pacto Internacional de Derechos Civiles y Políticos (1966). 